\title{
LKB1 couples glucose metabolism to insulin secretion in mice
}

\author{
Accalia $\mathrm{Fu}^{1,2} \cdot$ Karine Robitaille ${ }^{1} \cdot$ Brandon Faubert $^{3} \cdot$ Courtney Reeks $^{1}$. \\ Xiao-Qing Dai ${ }^{4}$ - Alexandre B. Hardy ${ }^{5}$ - Krishana S. Sankar ${ }^{6} \cdot$ Svetlana Ogrel $^{1}$. \\ Osama Y. Al-Dirbashi ${ }^{1,7}$. Jonathan V. Rocheleau ${ }^{6}$. Michael B. Wheeler ${ }^{3}$. \\ Patrick E. MacDonald ${ }^{4} \cdot$ Russell Jones $^{3} \cdot$ Robert A. Screaton $^{1,7,8,9}$
}

Received: 27 November 2014 / Accepted: 13 March 2015/Published online: 16 April 2015

(C) Springer-Verlag Berlin Heidelberg 2015

\begin{abstract}
Aims/hypothesis Precise regulation of insulin secretion by the pancreatic beta cell is essential for the maintenance of glucose homeostasis. Insulin secretory activity is initiated by the stepwise breakdown of ambient glucose to increase cellular ATP via glycolysis and mitochondrial respiration. Knockout of $L k b 1$, the gene encoding liver kinase B1 (LKB1) from the beta cell in mice enhances insulin secretory activity by an undefined mechanism. Here, we sought to determine the molecular basis for how deletion of $L k b 1$ promotes insulin secretion. Methods To explore the role of LKB1 on individual steps in the insulin secretion pathway, we used mitochondrial functional analyses, electrophysiology and metabolic tracing coupled with by gas chromatography and mass spectrometry. Results Beta cells lacking LKB1 surprisingly display impaired mitochondrial metabolism and lower ATP levels following glucose stimulation, yet compensate for this by upregulating both uptake and synthesis of glutamine, leading to
\end{abstract}

Electronic supplementary material The online version of this article (doi:10.1007/s00125-015-3579-7) contains peer-reviewed but unedited supplementary material, which is available to authorised users.

Robert A. Screaton

robert.screaton@sri.utoronto.ca

1 Children's Hospital of Eastern Ontario Research Institute, 401 Smyth Road, Ottawa K1H 8L1, Canada

2 Department of Biochemistry, Microbiology and Immunology, University of Ottawa, Ottawa, ON, Canada

3 Department of Physiology and Goodman Cancer Centre, McGill University, Montreal, QC, Canada

4 Alberta Diabetes Institute and Department of Pharmacology, University of Alberta, Edmonton, AB, Canada increased production of citrate. Furthermore, under low glucose conditions, $L \mathrm{kbl}^{-/-}$beta cells fail to inhibit acetyl-CoA carboxylase 1 (ACC1), the rate-limiting enzyme in lipid synthesis, and consequently accumulate NEFA and display increased membrane excitability.

Conclusions/interpretation Taken together, our data show that LKB1 plays a critical role in coupling glucose metabolism to insulin secretion, and factors in addition to ATP act as coupling intermediates between feeding cues and secretion. Our data suggest that beta cells lacking LKB1 could be used as a system to identify additional molecular events that connect metabolism to cellular excitation in the insulin secretion pathway.

Keywords ACC1 - AMPK - Glucose metabolism . Glutamine metabolism - Insulin secretion - LKB1 . Pancreatic beta cells
5 Department of Physiology, University of Toronto, Toronto, ON, Canada

6 Institute of Biomaterials and Biomedical Engineering, University of Toronto, Toronto, ON, Canada

7 Department of Pediatrics, University of Ottawa, Ottawa, ON, Canada

8 Department of Cellular and Molecular Medicine, University of Ottawa, Ottawa, ON, Canada

9 Present address: Sunnybrook Research Institute, 2075 Bayview Avenue, Toronto, ON M4N 3M5, Canada 


$\begin{array}{ll}\text { Abbreviations } \\ \text { ACC1 } & \text { Acetyl-CoA carboxylase 1 } \\ \text { AMPK } & \text { AMP-activated protein kinase } \\ \text { AP } & \text { Action potential } \\ \text { ECAR } & \text { Extracellular acidification rate } \\ \text { ETC } & \text { Electron transport chain } \\ \text { GFP } & \text { Green fluorescent protein } \\ \text { GSIS } & \text { Glucose-stimulated insulin secretion } \\ \alpha \text {-KG } & \alpha \text {-ketoglutarate } \\ \text {K}_{\text {ATP }} & \text { ATP-sensitive potassium channel } \\ \text { KIR6.2 } & \text { ATP-sensitive inward rectifier potassium channel } \\ \text { LABKO } & \text { Lkb1 adult beta cell knockout } \\ \text { LKB1 } & \text { Liver kinase B1 } \\ \text { LKB1i } & \text { LKB1 knockdown } \\ \text { L/L } & \text { LoxP/LoxP } \\ \text { MTG } & \text { Mitotracker green } \\ \text { OCR } & \text { Oxygen consumption rate } \\ \text { RRP } & \text { Readily releasable pool } \\ \text { shRNA } & \text { Short hairpin RNA } \\ \text { SUR1 } & \text { Sulfonylurea 1 } \\ \text { TCA } & \text { Tricarboxylic acid } \\ \text { TMRE } & \text { Tetramethylrhodamine ethyl ester }\end{array}$

\section{Introduction}

The initiating steps in the glucose-stimulated insulin secretion (GSIS) pathway involve the stepwise breakdown of glucose through glycolysis and oxidation of the glycolytic product, pyruvate, in mitochondria. ATP-sensitive potassium channels $\left(\mathrm{K}_{\mathrm{ATP}}\right.$ channels) on the plasma membrane sense the increase in ATP and consequently close [1-4], triggering membrane depolarisation and opening of voltage-sensitive L-type $\mathrm{Ca}^{2+}$ channels $[4,5]$. The secretory response is biphasic; within minutes a readily releasable pool (RRP) of granules docked at the plasma membrane is released [6-8]. A second phase, which requires recruitment and trafficking of insulin granules to the plasma membrane, follows [9]. The central role of the $\mathrm{K}_{\text {ATP }}$ channel in beta cell function is highlighted by deficiencies in both first and second phase GSIS in islets from sulfonylurea 1 (SUR1) ${ }^{-/}$and ATP-sensitive inward rectifier potassium channel (KIR6.2) ${ }^{-/-}$mice [10]. In humans, inappropriate inhibition or activation of $\mathrm{K}_{\mathrm{ATP}}$ channel activity arising from mutations in KIR6.2 and SUR1 underlie congenital hyperinsulinaemia or neonatal diabetes, respectively [11-13].

Our understanding of precisely how glucose is coupled to insulin output is still incomplete. Several lines of evidence have indicated that the secretory response is more intricate than the classical model outlined above would suggest. For example, an increase in cytosolic ATP and closure of $\mathrm{K}_{\text {ATP }}$ channels does not always correlate with insulin output in GSIS [10]. Beta cells can also secrete insulin independently of $\mathrm{K}_{\text {ATP }}$ channel closure by an unclear mechanism that still requires calcium influx and membrane depolarisation $[10,14]$. Furthermore, $\mathrm{K}_{\text {ATP }}$ channel activity can be recorded from oncell patches on beta cells exposed to glucose-free solutions, despite the fact that the intracellular ATP concentration under similar conditions would predict the channels to be closed [15]. Finally, the presence of depolarising agents and the allosteric $\mathrm{K}_{\text {ATP }}$ channel activator diazoxide can further enhance insulin secretion in response to glucose [16]. As a result, additional factors that drive metabolism-dependent secretion, such as mitochondrial metabolites (NADPH, GTP, phosphoenol pyruvate [PEP], $\alpha$-ketoglutarate $[\alpha-K G])$, and other secondary glucose-derived metabolites such as glutamate $[17,18]$ must exist.

We previously demonstrated that $L k b 1$ adult beta cell knockout (LABKO) mice are resistant to hyperglycaemia induced by a high-fat diet, owing in large part to a doubling of beta cell mass and enhanced insulin stores via mTOR activation [19]. However, targeting liver kinase B1 (LKB1) in the beta cell for the treatment of diabetes would be undesirable as knockout of $L k b 1$ in adult mice has a deleterious effect on haematopoietic stem cell maturation [20-22]. We and others have identified non-overlapping functions in beta cells for LKB 1 targets, including MAP/microtubule affinityregulating kinase 2 (MARK2), salt-inducible kinase 2 (SIK2), brain-specific kinase 2 (BRSK2) as well as AMPactivated protein kinase (AMPK) itself [19, 23-28], underscoring the potential for identifying the minimal target(s) of LKB1 responsible for enhancing insulin secretion. Here, we systematically interrogated insulin secretion pathway components to identify the signals responsible for enhanced insulin secretion in $L k b 1$ knockout islets.

\section{Methods}

Animals Control LoxP/LoxP (L/L) and LABKO mice were obtained from mating homozygous $L k b l$ floxed mice to $P d x 1-C r e E R^{\text {tam }}$ mice all on an FVB/n background as described previously [19] (electronic supplementary material [ESM] Methods).

Antibodies and short hairpin RNA sequences Antibodies and short hairpin RNA (shRNA) sequences are included in ESM Methods.

GSIS and calcium experiments GSIS and calcium experiments were performed as described previously [19] (ESM Methods).

Electron microscopy and insulin immunogold labelling Pancreases were fixed in $2.6 \%$ glutaraldehyde overnight and processed as described previously [29] (ESM Methods). 
Seahorse measurements Measurements of oxygen consumption rate (OCR) and extracellular acidification rate (ECAR) were performed as described previously [23] (ESM Methods).

Mitochondrial membrane potential and content measurements Mitochondrial inner membrane potential was measured in dispersed islet cells using tetramethylrhodamine ethyl ester (TMRE) and normalised to Mitotracker green (MTG; Invitrogen, Burlington, ON, Canada) intensity (ESM Methods).

NAD(P)H autofluorescence imaging Islets were incubated in $2 \mathrm{mmol} / \mathrm{l}$ glucose for $1 \mathrm{~h}$ and loaded into microfluidic devices and placed in a heating chamber on a Zeiss LSM710 microscope (Zeiss Canada, Toronto, ON, Canada) and imaged as described previously [30].

NEFA quantification in islets NEFA levels in chloroform extracts from 50 islets per mouse were determined using a colorimetric assay (Abcam, Toronto, ON, Canada).

Membrane potential recordings and whole cell patchclamp Plasma membrane potential and voltage-dependent $\mathrm{K}$ channel activity was measured using a perforated patch technique in whole cell configuration as described previously [31, 32] (ESM Methods).

Metabolomics $10^{6}$ MIN6 cells per condition were infected with lentivirus expressing non-silencing control or $L k b 1$ shRNA. At $72 \mathrm{~h}$ post-infection, cells were starved for $1 \mathrm{~h}$ in $\mathrm{KRBH}+1 \mathrm{mmol} / \mathrm{l}$ glucose prior to pulsing. Cells were pulsed with $10 \mathrm{mmol} / 1\left[\mathrm{U}_{-}{ }^{13} \mathrm{C}_{6}\right] \mathrm{glucose}$ or $2 \mathrm{mmol} / 1$ $\left[\mathrm{U}_{-}{ }^{13} \mathrm{C}_{5}\right]$ glutamine for the indicated times and compared with starved and unlabelled carbon source samples. GC-MS analysis was performed as described previously [33] (ESM Methods).

Measurement of ATP/ADP nucleotides Cells were processed for extraction of cell nucleotides as described previously [34] (ESM Methods).

\section{Results}

Loss of LKB1 in mouse beta cells increases insulin granule size and plasma membrane docking We previously reported that islets lacking LKB1 in the beta cell compartment led to a twofold increase in insulin content per cell [19]. As the proximity of insulin granules to the plasma membrane dictates the amplitude of first phase insulin release, we evaluated the size of the RRP in LABKO islets. Electron microscopy revealed that the number of insulin granules docked at the plasma membrane was $60 \%$ greater in LABKO beta cells, which correlated well with the 1.9-fold increase in first phase GSIS (Fig. 1a, b). Insulin immunogold labelling revealed a greater than twofold increase in the number of insulinpositive particles per granule, and a greater than threefold increase in the number of large granules ( $>900 \mathrm{~nm}$ diameter; ESM Fig. 1).

LKB1 regulates glucose sensing We previously observed an enhanced rate of calcium influx in response to glucose in LKB1 knockdown (LKB1i) MIN6 cells, raising the possibility that LKB1 regulates sensitivity to feeding cues. To determine if glucose responsiveness is enhanced in the absence of LKB1, we performed islet perifusion experiments. A glucose ramp (2.8 to $16.7 \mathrm{mmol} / \mathrm{l})$ revealed an increase in maximal release at near saturating glucose concentrations in the GSIS response curve, with the response from LABKO islets to $8 \mathrm{mmol} / \mathrm{l}$ glucose equal to that of $\mathrm{L} / \mathrm{L}$ control islets to $16.7 \mathrm{mmol} / \mathrm{l}$ glucose (Fig. 1c). Taken together, these data suggest that, in addition to having an increase in insulin cargo per cell, LABKO beta cells are also more sensitive to glucose.
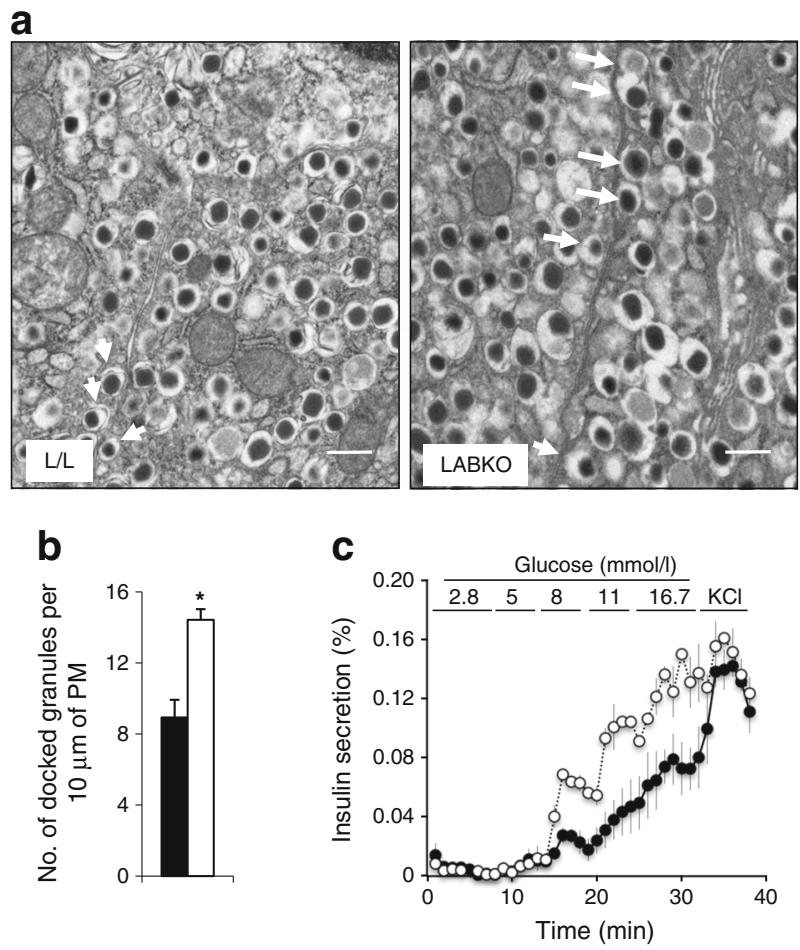

Fig. 1 Loss of LKB1 in mouse beta cells increases insulin granule size and plasma membrane docking. (a, b) The number of docked insulin granules quantified in $\mathrm{L} / \mathrm{L}$ control (black bar) and LABKO (white bar) beta cells as the number of granules found within $100 \mathrm{~nm}$ of the plasma membrane (docked granules highlighted by white arrows; ${ }^{*} p>0.05,10$ 20 fields per mouse were quantified, $n=3$ per genotype); scale bar, $500 \mathrm{~nm}$. (c) Insulin secretion (as \% of total insulin content) measured during perifusion of isolated $\mathrm{L} / \mathrm{L}$ control (black circles) and $\mathrm{LABKO}$ (white circles) islets at increasing glucose concentrations and $45 \mathrm{mmol} / \mathrm{l}$ $\mathrm{KCl}$. Data are $\pm \mathrm{SEM}, n=3$ per genotype, representative of three independent experiments. PM, plasma membrane 
LKB1 depletion increases sensitivity to the anti-diabetic drug tolbutamide To determine if the $\mathrm{K}_{\mathrm{ATP}}$ channel was functionally altered in cells lacking LKB1, we monitored insulin secretion in response to tolbutamide, which belongs to a class of sulfonylurea drugs used to treat type 2 diabetes. Binding of tolbutamide to the SUR1 subunit of the $\mathrm{K}_{\text {ATP }}$ channel results in channel closure, membrane depolarisation and insulin secretion. Following treatment of MIN6 cells expressing control non-silencing shRNA with $200 \mu \mathrm{mol} / 1$ tolbutamide, we observed an eightfold stimulation of insulin secretion in $1 \mathrm{mmol} / \mathrm{l}$ (low) glucose and 17-fold stimulation in the presence of $20 \mathrm{mmol} / \mathrm{l}$ (high) glucose (Fig. 2a). Interestingly, following knockdown of LKB1, MIN6 cells in low glucose responded to tolbutamide as though they were cultured in stimulatory glucose concentrations (Fig. 2a). This effect was also seen in perifused LABKO islets, which unlike islets from control (L/L) animals, secreted insulin in response to tolbutamide in low glucose (Fig. 2b). Treatment of LABKO islets
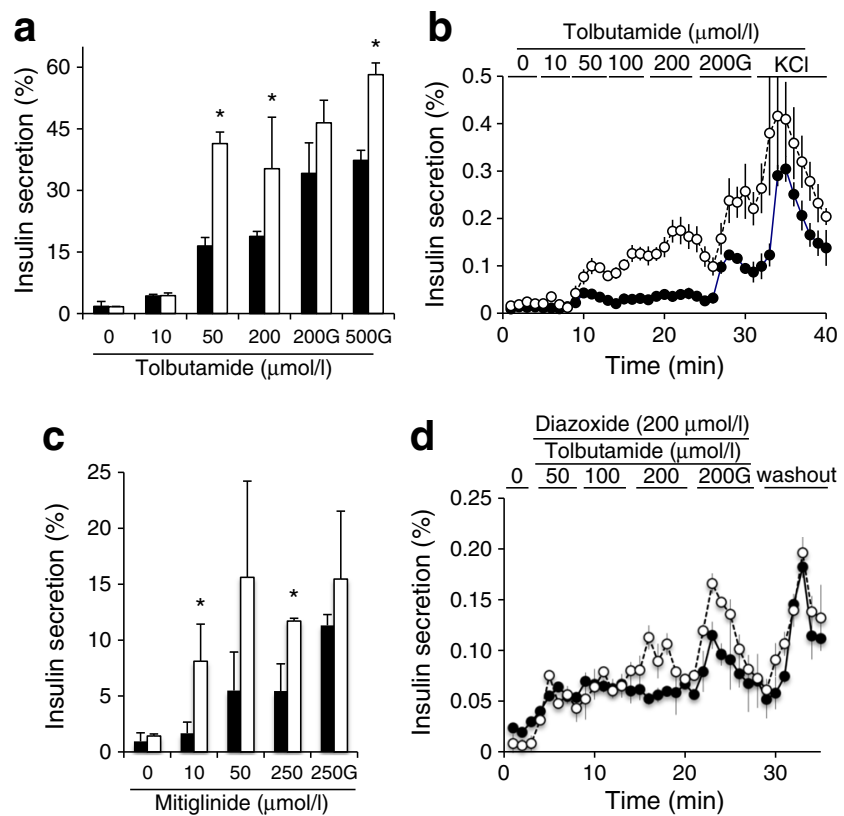

Fig. 2 LKB1 depletion increases sensitivity to the glucose-lowering drug tolbutamide. (a) Insulin secretion measured in MIN6 cells expressing non-silencing control shRNA (NSi, black bars) or Lkbl-targeting shRNA (LKB1i, white bars) following tolbutamide treatment. Effect of combined treatment with 200 or $500 \mu \mathrm{mol} / 1$ tolbutamide with $20 \mathrm{mmol} / 1$ glucose (G) is shown. (b) Insulin secretion in perifused L/L (black circles) and LABKO (white circles) islets following tolbutamide (50-200 $\mu \mathrm{mol} / \mathrm{l})$ treatment ( $n=3$ per genotype). (c) Insulin secretion in L/L (black bars) and LABKO (white bars) islets following static incubations in mitiglinide $(10-250 \mu \mathrm{mol} / \mathrm{l})$ and $250 \mu \mathrm{mol} / \mathrm{l}$ in the presence of $16.7 \mathrm{mmol} / \mathrm{l}$ glucose ( $n=3-4$ per genotype). (d) Insulin secretion from perifused L/L control (black circles) and LABKO (white circles) islets during addition of increasing concentrations of tolbutamide in the presence of diazoxide $(200 \mu \mathrm{mol} / \mathrm{l})$ and following a $10 \mathrm{~min}$ washout period in $2.8 \mathrm{mmol} / \mathrm{l} \mathrm{glu}-$ cose $\left(n=3\right.$ per genotype). All data are $\pm \mathrm{SD}\left({ }^{*} p<0.05\right)$ and representative of three independent experiments in (a) and (c) and representative of two independent experiments in (b) and (d). Insulin secretion in (a-d) is expressed as per cent of total insulin content with mitiglinide, a secretagogue that closes the $\mathrm{K}_{\text {ATP }}$ channel without binding to SUR1, produced similar results (Fig. 2c). To determine if closure of the $\mathrm{K}_{\mathrm{ATP}}$ channel was required for the observed sensitisation, we stimulated LABKO islets with increasing amounts of tolbutamide in the presence of diazoxide, which opens the $\mathrm{K}_{\mathrm{ATP}}$ channel and prevents membrane depolarisation and insulin secretion [35]. As shown in Fig. 2d, both LABKO and control islets responded to tolbutamide in the presence of diazoxide, indicating that if LKB1 acts on the $\mathrm{K}_{\mathrm{ATP}}$ channel it likely does so in a SUR1-independent manner, a mechanism that has been reported for glucosestimulated secretion (reviewed in [36]).

Enhanced membrane depolarisation and calcium influx in LABKO beta cells The sensitivity to tolbutamide in LABKO cells suggested that closure of $\mathrm{K}_{\mathrm{ATP}}$ channels could occur at a lower threshold, either because there are fewer channels present, or because the channels are more primed for closure at steady state. Whole cell patch-clamp analysis showed that LABKO beta cells fire action potentials (APs) at sixfold lower concentration of tolbutamide than control beta cells (100 $\mu \mathrm{mol} / 1$ for control L/L, $15 \mu \mathrm{mol} / 1$ for LABKO; Fig. 3a, b), and that the frequency of APs in LABKO beta cells increased twofold to fivefold overall at either concentration of drug (Fig. 3b). Surprisingly, both resting membrane potential and the magnitude of depolarisation in response to glucose treatment were similar in control and LABKO beta cells, suggesting that $\mathrm{K}_{\mathrm{ATP}}$ channel closure is still dynamically regulated (Fig. 3c; ESM Fig. 2a). Furthermore, the $\mathrm{K}_{\text {ATP }}$ channel density was the same in $\mathrm{L} / \mathrm{L}$ and $\mathrm{LABKO}$ beta cells (Fig. 3d). Importantly, there was no change in expression of $\mathrm{K}_{\mathrm{ATP}}$ channel subunits in MIN6 LKB1i cells or LABKO islets, and no enhancement in $\mathrm{K}_{\text {ATP }}$ channel closure in LABKO islets following glucose treatment (ESM Fig. 2b). These data indicate that loss of LKB1 enhances cellular excitability through promoting calcium influx and not through regulating $\mathrm{K}_{\text {ATP }}$ channel closure.

Consistent with the increased tolbutamide-induced membrane depolarisation, maximal calcium response to tolbutamide in MIN6 cells was achieved at a tenfold lower concentration after silencing LKB1 (Fig. 3e), while calcium levels under basal conditions were unaffected (ESM Fig. 3a). A similar effect was observed in dispersed LABKO beta cells (ESM Fig. 4a). Treatment with the L-type specific calcium channel inhibitor diltiazem blocked this influx, indicating that the extracellular milieu and not intracellular stores was the source of calcium ions (ESM Fig. $4 \mathrm{a}, \mathrm{b}$ ). Taken together, these data reveal that LABKO beta cells secrete more insulin in part due to sensitisation of calcium influx.

LKB1 is required for mitochondrial respiration in beta cells Mitochondrial oxidative phosphorylation using the glycolytic end-product pyruvate generates ATP that closes $\mathrm{K}_{\text {ATP }}$ 
a

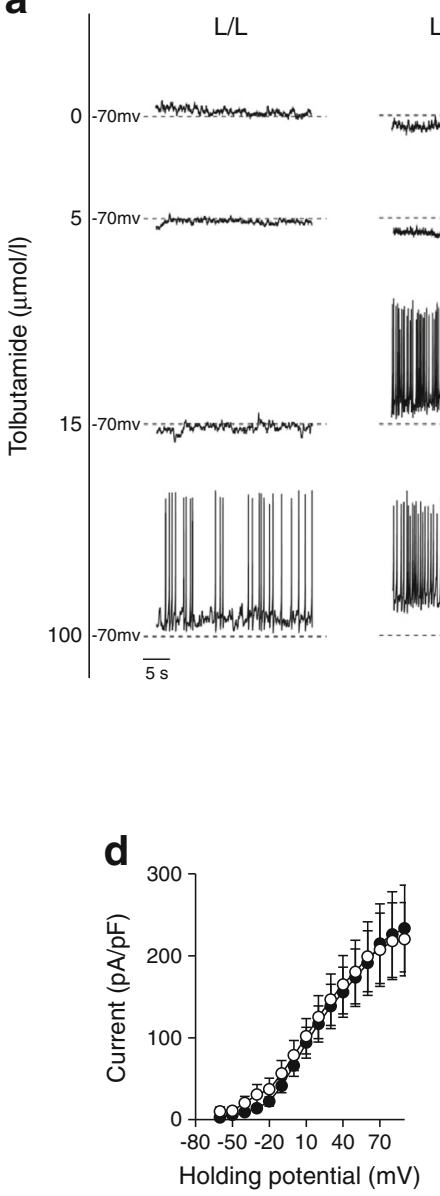

b

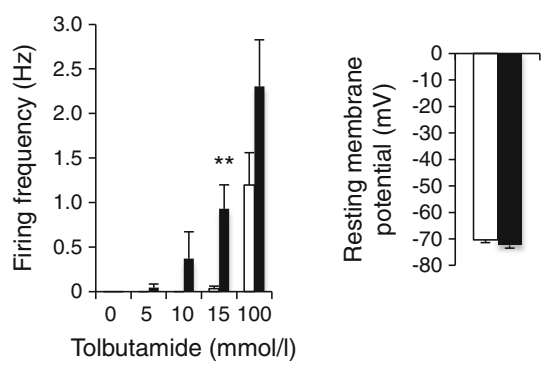

C
LABKO


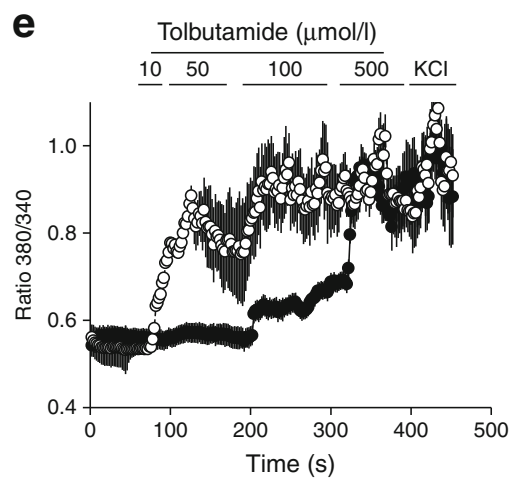

Fig. 3 Enhanced membrane depolarisation in LABKO beta cells is calcium-influx-dependent. (a) Representative traces of AP firing in $\mathrm{L} / \mathrm{L}$ and LABKO beta cells under perforated whole cell patch conditions following tolbutamide treatment. (b) Quantification of 11 and 12 beta cells from $\mathrm{L} / \mathrm{L}$ (white bars) and LABKO (black bars) mice were pooled from three independent experiments showing AP frequency in response to tolbutamide; ${ }^{* *} p<0.01$. (c) Quantification of resting membrane potential of $\mathrm{L} / \mathrm{L}$ (white bar; $n=11$ ) vs LABKO (black bar; $n=12$ ) beta cells in $2.8 \mathrm{mmol} / 1$ glucose. (d) Mean voltage-activated $\mathrm{K}^{+}$current from whole cell patch- clamped beta cells from $\mathrm{L} / \mathrm{L}$ (white circles; wild-type; $n=8$ cells) and LABKO (black circles; KO; $n=10$ cells) mice. Data are \pm SD. (e) $\mathrm{Ca}^{2+}$ influx following treatment with tolbutamide (50-200 $\mu \mathrm{mol} / \mathrm{l})$, using the ratio of 380/340 excitation of Fura-2-acetoxymethyl ester (Fura2AM) dye in control shRNA (black circles) and LKB1i (white circles) MIN6 cells. Treatment with depolarising agent $(45 \mathrm{mmol} / \mathrm{l} \mathrm{KCl})$ to compare total cytosolic $\mathrm{Ca}^{2+}$ capacity is shown. Data are \pm SEM and are pooled averages from three independent experiments with $n=3$ replicates each channels and amplifies the insulin secretory response. The accelerated glucose responsiveness and calcium influx seen in LKB1 knockdown cells (Fig. 1b) prompted us to test whether loss of LKB1 enhances mitochondrial function. In control MIN6 cells and control (L/L) islets, the OCR increased in response to glucose (Fig. 4a, b). By contrast, LKB1 knockdown MIN6 cells and LABKO islets displayed a global reduction in OCR, to levels at or below which control MIN6 cells and L/L islets OCR respired following treatment with oligomycin, an inhibitor of mitochondrial F1Fo-ATP synthase (Fig. 4a, b). The effects on both respiration and insulin secretion were specific to loss of LKB1, as reconstitution of LKB1 in LABKO islets restored the OCR (Fig. 4c) and reduced GSIS in both primary mouse islets (Fig. 4b) and LABKO islets (ESM Fig. 5a). These data indicate a surprising uncoupling of insulin secretory capacity and mitochondrial bioenergetics in beta cells lacking LKB1. MIN6 cells, unlike primary islets [37], will metabolise pyruvate and consequently secrete insulin. Interestingly, provision of pyruvate or the anaplerotic substrate glutamine (see below) individually or in combination restored OCR in both basal and uncoupled states in cells lacking LKB1 (Fig. 4c, d; ESM Fig. 5b, c). Normal OCR was restored when green fluorescent protein (GFP)-tagged LKB1 was introduced into LABKO islets (Fig. 4e) or by overexpression of a constitutively active AMPK (AMPK-T172D), indicating that loss of AMPK activity at least in part resulted in the respiratory defect (ESM Fig. 5d). Consistent with this, overexpression of LKB1 in control islets inhibited secretion (Fig. 4f).

The reduction in medium ECAR in LABKO cells (ESM Fig. 5b) suggested that impaired generation of a metabolic intermediate may underlie the defect in mitochondrial 



Fig. 4 LKB1 is required for mitochondrial respiration in beta cells. (a, b) OCR normalised to total $\mu \mathrm{g}$ of protein, in (a) non-silencing control shRNA (NSi) and LKB1i MIN6 cells and (b) dissociated L/L and LABKO islets. In (a-d), control cells are represented by black circles and LKB1i/LABKO by white circles. Treatments were as follows: $16.7 \mathrm{mmol} / \mathrm{l}$ glucose $(\mathrm{G})$ and $5 \mu \mathrm{mol} / \mathrm{l}$ oligomycin $(\mathrm{O})$. (c, d) OCR normalised to total $\mu \mathrm{g}$ of protein, in (c) NSi and LKB1i MIN6 cells and (d) dissociated $\mathrm{L} / \mathrm{L}$ and $\mathrm{LABKO}$ islets in the presence of $2 \mathrm{mmol} / \mathrm{l}$ pyruvate and $4 \mathrm{mmol} / \mathrm{l}$ glutamine. F, FCCP; R, rotenone. (e) OCR normalised to total $\mu \mathrm{g}$ of protein measured in $\mathrm{L} / \mathrm{L}$ (black symbols) and LABKO (white symbols) islets infected with Adeno-GFP (circles) or Adeno-LKB1 (squares). OCR at baseline and following $16.7 \mathrm{mmol} / \mathrm{l}$ glucose $(\mathrm{G})$ and $5 \mu \mathrm{mol} / \mathrm{l}$ oligomycin $(\mathrm{O})$ are shown. Western blotting of protein extracts from parallel samples is shown. KO, LABKO. (f) Insulin secretion from

wild-type mouse islets overexpressing empty vector (EV)-GFP or LKB1GFP in low glucose $(2.8 \mathrm{mmol} / \mathrm{l}$; white bars) or high glucose $(16.7 \mathrm{mmol} /$ 1; black bars). Endogenous (endog.) LKB1 is indicated. Data are \pm SEM from $n=2$ mice per condition. Western blot for protein levels is shown. (g) Fold change of ATP/ADP ratio in NSi (black bars) and LKB1i (white bars) MIN6 cells after glucose stimulation $(20 \mathrm{mmol} / \mathrm{l})$. Data are $\pm \mathrm{SEM}$ of two independent experiments. (h) Mitochondrial membrane potential in dissociated $\mathrm{L} / \mathrm{L}$ (black circles) and LABKO (white circles) islets using relative fluorescence intensity (RFU) of TMRE:MTG following treatment with $16.7 \mathrm{mmol} / 1$ glucose $(\mathrm{G})$ and $50 \mu \mathrm{mol} / 1$ carbonyl cyanide-4(trifluoromethoxy)phenylhydrazone (FCCP). Data are pooled from $n=3$ per genotype, with AUC inset expressed in arbitrary area units, and are \pm SEM

respiration. Indeed, we observed a reduced ATP/ADP ratio in MIN6 cells (Fig. 4g) as well as lower ATP levels and mitochondrial membrane potential $(\Delta \Psi)$ in LABKO islets (Fig. 4h; ESM Fig. 6). These changes occurred without a reduction in mitochondrial mass (ESM Fig. 7). These data indicate that if provided with sufficient fuel, the electron transport chain (ETC) in LKB1-deficient cells can support electron transport.

Increased glutamine flux in beta cells lacking LKB1 To determine if impaired bioenergetics in LABKO cells was due to a defect in generation of mitochondrial fuel, we assessed the metabolic flux of glucose in LABKO islets by GC-MS. Following timed pulses with $10 \mathrm{mmol} / 1\left[{ }^{13} \mathrm{C}_{6}\right]$ glucose, there was an overall trend towards increased total pyruvate in MIN6 cells silenced for $L k b 1$, derived from both labelled $\left({ }^{13} \mathrm{C}\right)$ and unlabelled $\left({ }^{12} \mathrm{C}\right)$ sources (Fig. 5a, b). A significant increase in pyruvate was only observed in the relative

abundance of $\left[{ }^{12} \mathrm{C}\right]$ pyruvate after $120 \mathrm{~min}$, consistent with a reduction in its rate of production from glucose. We also observed a significant increase in unlabelled citrate in the absence of LKB1 at all time points (Fig. 5b). However, the proportion of ${ }^{13} \mathrm{C}$-labelling of citrate from glucose was similar in cells lacking LKB1, suggesting that tricarboxylic acid (TCA)-derived citrate from glucose was reduced, in a similar fashion to pyruvate. Following $L k b 1$ silencing, glucose flux to $\alpha-\mathrm{KG}$ was also decreased, suggesting the excess pyruvate and citrate have an alternate fate besides cycling through the TCA cycle.

Interestingly, levels of glucose-derived glutamine were elevated in LKB1 knockdown cells (Fig. 5b), which can be used as an alternative cellular carbon source for anabolic processes. To identify the fate of glutamine, we pulsed MIN6 cells with $2 \mathrm{mmol} / 1\left[{ }^{13} \mathrm{C}_{5}\right]$ glutamine for 10 and $60 \mathrm{~min}$ and measured incorporation into several intermediate metabolites using GCMS (Fig. 5c). In cells silenced for $L k b 1$, there was a trend 
Fig. 5 Increased glutamine flux in beta cells lacking LKB1. (a) Schematic showing the fate of ${ }^{13} \mathrm{C}$ and ${ }^{12} \mathrm{C}$ glucose labels into downstream TCA intermediates. Quantification of relative abundance (amount of metabolite in LKB1i cells compared with the corresponding amount in nonsilencing control shRNA [NSi] cells) of ${ }^{13} \mathrm{C}$ (black bars) and ${ }^{12} \mathrm{C}$ (white bars) in pyruvate (b), citrate (c), $\alpha-\mathrm{KG}(\mathbf{d})$ and glutamine (e) isolated from MIN6 cells infected with $\mathrm{NSi}(\mathrm{N})$ or LKB1i (L) shRNA lentivirus following a 10 or $120 \mathrm{~min}$ pulse with $\left[{ }^{13} \mathrm{C}_{6}\right]$ glucose. (f) Schematic showing the fate of ${ }^{13} \mathrm{C}$ and ${ }^{12} \mathrm{C}$ in metabolites downstream of glutamine. Relative ${ }^{13} \mathrm{C}$ (black bars) and ${ }^{12} \mathrm{C}$ (white bars) levels of $\left[{ }^{13} \mathrm{C}\right]$ - and $\left[{ }^{12} \mathrm{C}\right]$ glutamine $(\mathrm{g})$, glutamate (h), $\alpha$-KG (i) and citrate (j) isolated from MIN6 cells transfected with $\mathrm{NSi}(\mathrm{N})$ or LKB1i (L) siRNA cells following a 10 or 60 min pulse with $\left[{ }^{13} \mathrm{C}_{5}\right]$ glutamine. Samples in $(\mathbf{b}-\mathbf{j})$ are from $n=4$ independent experiments, data are $\pm \mathrm{SEM}$, ${ }^{*} p<0.05 ; * * p<0.01$; $* * * p<0.001$ a

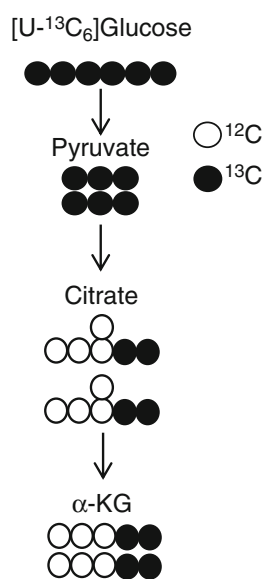

f

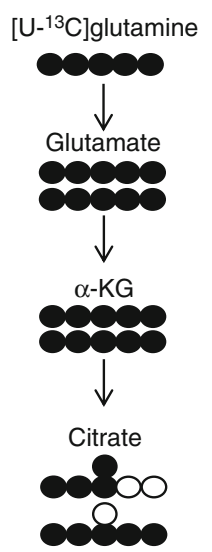

b



d

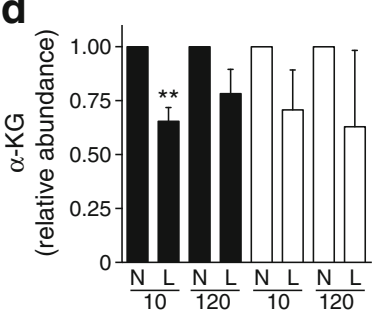

g



i

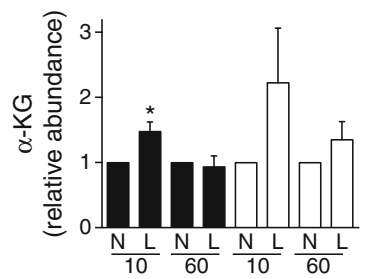

C

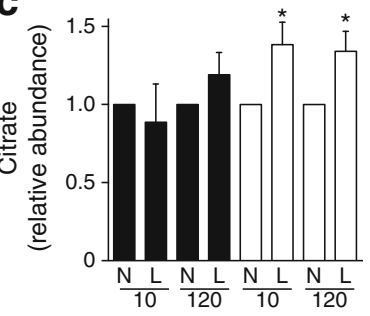

e



h

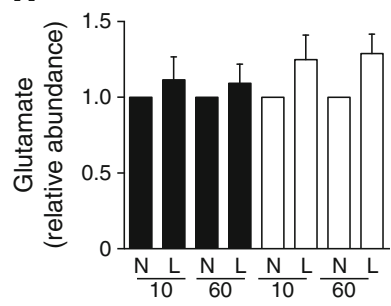

j

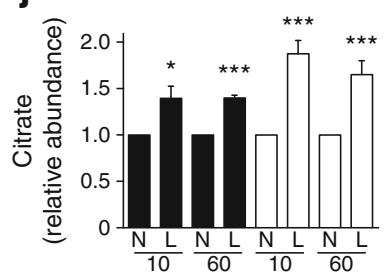

towards increased glutamine uptake and levels of glutamate, as well as a significant early increase in $\alpha$-KG levels (Fig. 5d). Furthermore, while pyruvate levels were unaffected, citrate production from glutamine was significantly increased at all time points (Fig. $5 \mathrm{~d}$ and data not shown). Taken together, these data indicate that in beta cells lacking LKB1, the breakdown of glucose is enhanced, resulting in an increase in citrate and glutamine abundance. That this occurs in the absence of a corresponding increase in glucose-derived TCA intermediates indicates that citrate is being redirected away from the TCA cycle and used for other biosynthetic pathways. Consistent with this observation, labelled carbons from glutamine contribute less to $\alpha-K G$ than to citrate, suggesting that this pool of citrate is shunted away from $\alpha-\mathrm{KG}$ production.

Enhanced acetyl-CoA carboxylase 1 activity is required for insulin in LABKO islets To determine if changes in reductive potential accompany the enhanced insulin secretion phenotype in cells lacking LKB1, we measured levels of
$\mathrm{NAD}(\mathrm{P}) \mathrm{H}$, a proposed coupling factor for insulin secretion, in both mitochondrial and cytosolic fractions. While we observed glucose-dependent increases in NAD(P)H levels, these were unaffected by silencing $L k b l$ (Fig. 6a). Recent evidence indicates that in cancer cells, increased citrate can be generated in a reverse reaction that uses glutamine as a substrate known as reductive carboxylation [38]. Reductive carboxylation provides carbon for fatty acid synthesis and drives the accumulation of long chain fatty acids [38]. We therefore measured levels of NEFA (of longer than eight carbons) in LABKO islets and found they were increased twofold compared with control islets (Fig. 6b). Using labelled glucose and glutamine during $24 \mathrm{~h}$ to trace NEFA in LKB1i cells, we were unable to identify which NEFA was increased in LKBi cells, mainly due to the very small proportion of NEFA being produced from both glucose and glutamine (data not shown). However consistent with the overall increase of NEFA LABKO islets, phosphorylation of acetyl-CoA carboxylase 1 (ACC1; at the AMPK site Ser79 [39]) was reduced by 
a



b

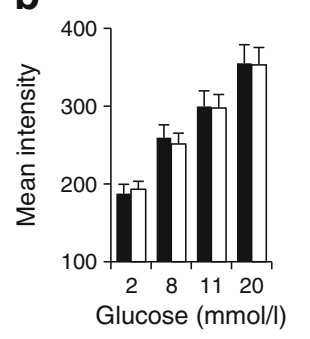

d

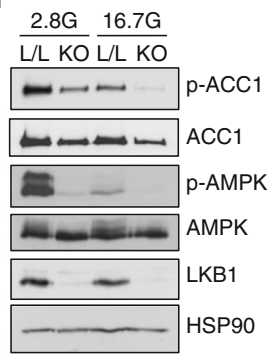

e

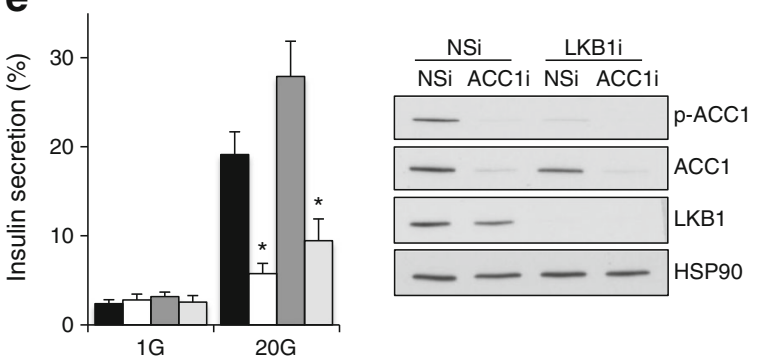

Fig. 6 Depletion of LKB1 activates ACC1 activity and insulin secretion. Autofluorescence intensity of (a) cytosolic and (b) mitochondrial $\mathrm{NAD}(\mathrm{P}) \mathrm{H}$ pools at $705 \mathrm{~nm}$ in indicated concentrations of glucose. Control, black bars; LKB1i/LABKO, white bars. (c) Measurement of NEFA levels from $\mathrm{L} / \mathrm{L}$ (black bar) and LABKO (white bar) islets cultured in RPMI. (d) Western blots showing p-ACC1, total ACC1, p-AMPK, total AMPK, LKB1 and heat-shock protein 90 (HSP90) protein levels in L/L and LABKO islets cultured in low or high glucose (G). Quantification of p-ACC1:total ACC1 levels in L/L (black bars) and LABKO (white bars) is shown. (e) Insulin secretion from MIN6 cells cultured in low or high glucose after silencing $L k b 1$ (LKB1i, dark grey bars) or Accl alone (ACCli, white bars) or together (light grey bars) compared with nonsilencing control shRNA (NSi) (black bars). Western blot showing ACC1 knockdown is shown. Data are \pm SEM, where ${ }^{*} p<0.01$ pooled from three independent experiments

$50 \%$ in LABKO islets, indicative of inappropriate ACC1 activation under low glucose conditions, which we attribute to a loss of AMPK activity (Fig. 6c). These observations suggest that ACC1-dependent lipid accumulation may be important for insulin secretion; indeed, knockdown of ACC1 blocked insulin secretion in MIN6 cells and in mouse islets even when Lkb1 was silenced (Fig. 6d; ESM Fig. 8). Taken together, these data show that LKB1 functions to restrain glucosestimulated calcium influx and insulin secretion by attenuating $\mathrm{ACC} 1$ activity and the generation of glutamine-derived citrate (see model in Fig. 7).

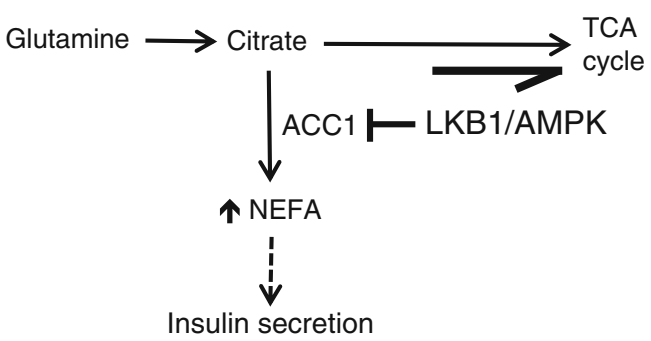

Fig. 7 Model showing the role of LKB1 in the regulation of glucosederived metabolites in pancreatic beta cells. LKB1/AMPK blocks ACC1, increasing the pool of citrate available for anaplerosis. In the absence of LKB1, ACC1 activity is elevated, promoting fatty acid accumulation and GSIS. ACL, ATP citrate lyase

\section{Discussion}

LKB1 depletion uncouples glucose metabolism from calcium influx and insulin secretion We and others previously reported that deletion of $L k b l$ in adult mouse beta cells leads to increased insulin secretion $[19,26]$. Here, we report that LKB1 acts to attenuate $\mathrm{K}_{\text {ATP }}$ channel closure and calcium influx. This is evidenced by an enhanced closure of $\mathrm{K}_{\mathrm{ATP}}$ channels, calcium influx and insulin secretion in response to tolbutamide in LABKO beta cells, even in the absence of glucose. Given the reduction in energy status in LABKO beta cells under both basal and stimulated conditions, the enhancement in insulin secretion is paradoxical. Taken together, our data are consistent with the notion that LKB1 regulates both exocytotic events as well as metabolic amplification of calcium influx through an alternate coupling factor that is not ATP and involves citrate and $\mathrm{ACC} 1$.

Metabolic rewiring in LABKO beta cells That impaired mitochondrial respiration in LABKO islets can be restored with constitutively active AMPK indicates the LKB1AMPK pathway may directly control mitochondrial bioenergetics. While provision of additional substrate can restore full ETC activity in beta cells lacking LKB1, following glucose stimulation there is a reduction by half in their bioenergetic capacity. Furthermore, in the absence of LKB1, glucose usage favours citrate and glutamine production, and glucose-derived glutamine is used to generate citrate, contributing to higher citrate levels. This metabolic shift towards glutaminolysis may help to maintain both the higher basal mitochondrial membrane potential and NADPH levels in LABKO $\beta$ cells in which respiration is attenuated. Glutamine itself is known to amplify GSIS and enhance $\mathrm{K}_{\text {АTP }}$ channel-independent release [40], and may serve as a coupling factor to amplify metabolism-secretion coupling in LABKO beta cells. This idea is consistent with recent work using beta cells in which $L k b 1$ is deleted (using the Ins1-Cre system), wherein loss of LKB1 or AMPK results in a metabolic switch favouring glutamine metabolism [27]. 
Taken together, it appears that in cells lacking LKB1, fuel is redirected away from the TCA cycle to favour biosynthetic pathways such as amino acid synthesis, or NEFA and lipid generation for de novo granule generation, or perhaps for use in a signalling role. As ACC1 has been shown to be required for pyruvate cycling and generation of TCA intermediates [41, 42], we conclude that enhanced insulin secretion from LABKO beta cells is due at least in part to enhanced ACC1 activity and increased citrate production from glutamine. Taken together, these observations support the idea that activating ACC1 or elevating citrate levels may be beneficial for enhancing insulin secretion in settings of hypoinsulinaemia.

Acknowledgements We would like to acknowledge members of the Screaton laboratory for helpful discussions and commentary on the manuscript, T. Alves and R. Kibbey (Department of Internal Medicine, Yale University, New Haven, CT, USA) for assistance with metabolomics studies and helpful discussions, P. Rippstein (University of Ottawa Heart Institute, Ottawa, Canada) for assistance with Electron Microscopy, J. McBane (University of Ottawa, Ottawa, ON, Canada) for assistance with islet isolations. Adenovirus expressing AMPK-CA was a kind gift of J. Dyck (Department of Pediatrics, University of Alberta, Edmonton, AB, Canada).

Funding This work was supported by grants to RAS from the Canadian Institutes of Health Research (CIHR; MOP \#111186), Canadian Foundation for Innovation (CFI), and by a Studentship from the Canadian Diabetes Association to AF. RAS acknowledges the Canada Research Chair program for support.

Duality of interest The authors declare that there is no duality of interest associated with this manuscript.

Contribution statement $\mathrm{AF}$ researched data and wrote the manuscript. $\mathrm{KR}, \mathrm{BF}$ and $\mathrm{ABH}$ researched data and edited the manuscript. $\mathrm{CR}, \mathrm{XQD}$, $\mathrm{KSS}, \mathrm{SO}$ and JVR researched data and revised the article. OYAD, MBW and PEM designed methods, supervised data acquisition and edited the manuscript. RJ contributed to project design, supervised data acquisition and edited the manuscript. RAS designed the project and wrote the manuscript. All authors approved the final version. RAS is the guarantor of this work.

\section{References}

1. Maechler P, Li N, Casimir M, Vetterli L, Frigerio F, Brun T (2010) Role of mitochondria in beta-cell function and dysfunction. Adv Exp Med Biol 654:193-216

2. Tarasov A, Dusonchet J, Ashcroft F (2004) Metabolic regulation of the pancreatic beta-cell ATP-sensitive $\mathrm{K}+$ channel: a pas de deux. Diabetes 53(Suppl 3):S113-S122

3. Inagaki N, Gonoi T, Clement JP et al (1995) Reconstitution of IKATP: an inward rectifier subunit plus the sulfonylurea receptor. Science 270:1166-1170

4. MacDonald PE, Joseph JW, Rorsman P (2005) Glucose-sensing mechanisms in pancreatic beta-cells. Philos Trans R Soc Lond B Biol Sci 360:2211-2225

5. Arkhammar P, Nilsson T, Rorsman P, Berggren PO (1987) Inhibition of ATP-regulated $\mathrm{K}+$ channels precedes depolarizationinduced increase in cytoplasmic free $\mathrm{Ca} 2+$ concentration in pancreatic beta-cells. J Biol Chem 262:5448-5454
6. Olofsson CS, Gopel SO, Barg S et al (2002) Fast insulin secretion reflects exocytosis of docked granules in mouse pancreatic B cells. Pflugers Arch 444:43-51

7. Barg S, Eliasson L, Renstrom E, Rorsman P (2002) A subset of 50 secretory granules in close contact with L-type $\mathrm{Ca} 2+$ channels accounts for first-phase insulin secretion in mouse beta-cells. Diabetes 51(Suppl 1):S74-S82

8. Jewell JL, Oh E, Thurmond DC (2010) Exocytosis mechanisms underlying insulin release and glucose uptake: conserved roles for Munc18c and syntaxin 4. Am J Physiol Regul Integr Comp Physiol 298:R517-R531

9. Tsushima RG (2011) Second-phase insulin secretion gets cool. Am J Physiol Endocrinol Metab 301:E1070-E1071

10. Seghers V, Nakazaki M, DeMayo F, Aguilar-Bryan L, Bryan J (2000) Sur1 knockout mice. A model for K(ATP) channelindependent regulation of insulin secretion. J Biol Chem 275: 9270-9277

11. Pratt EB, Yan FF, Gay JW, Stanley CA, Shyng SL (2009) Sulfonylurea receptor 1 mutations that cause opposite insulin secretion defects with chemical chaperone exposure. J Biol Chem 284:7951-7959

12. Tammaro P, Girard C, Molnes J, Njolstad PR, Ashcroft FM (2005) Kir6.2 mutations causing neonatal diabetes provide new insights into Kir6.2-SUR1 interactions. EMBO J 24:2318-2330

13. Aittoniemi J, Fotinou C, Craig TJ, de Wet H, Proks P, Ashcroft FM (2009) Review. SUR1: a unique ATP-binding cassette protein that functions as an ion channel regulator. Philos Trans R Soc Lond B Biol Sci 364:257-267

14. Seino Y, Miki T, Fujimoto W et al (2013) Cephalic phase insulin secretion is KATP channel independent. J Endocrinol 218:25-33

15. Hohmeier HE, Mulder H, Chen G, Henkel-Rieger R, Prentki M, Newgard CB (2000) Isolation of INS-1-derived cell lines with robust ATP-sensitive $\mathrm{K}+$ channel-dependent and -independent glucose-stimulated insulin secretion. Diabetes 49:424-430

16. Sato Y, Henquin JC (1998) The K+-ATP channel-independent pathway of regulation of insulin secretion by glucose: in search of the underlying mechanism. Diabetes 47:1713-1721

17. Gheni G, Ogura M, Iwasaki M et al (2014) Glutamate acts as a key signal linking glucose metabolism to incretin/cAMP action to amplify insulin secretion. Cell Rep 9:661-673

18. Feldmann N, del Rio RM, Gjinovci A, Tamarit-Rodriguez J, Wollheim CB, Wiederkehr A (2011) Reduction of plasma membrane glutamate transport potentiates insulin but not glucagon secretion in pancreatic islet cells. Mol Cell Endocrinol 338:46-57

19. Fu A, Ng AC, Depatie C et al (2009) Loss of Lkb1 in adult beta cells increases beta cell mass and enhances glucose tolerance in mice. Cell Metab 10:285-295

20. Gurumurthy S, Xie SZ, Alagesan B et al (2010) The Lkb1 metabolic sensor maintains haematopoietic stem cell survival. Nature 468:659-663

21. Nakada D, Saunders TL, Morrison SJ (2010) Lkb1 regulates cell cycle and energy metabolism in haematopoietic stem cells. Nature 468:653-658

22. Gan B, Hu J, Jiang S et al (2010) Lkb1 regulates quiescence and metabolic homeostasis of haematopoietic stem cells. Nature 468: 701-704

23. Sakamaki JI, Fu A, Reeks C et al (2014) Role of the SIK2-p35PJA2 complex in pancreatic beta-cell functional compensation. Nat Cell Biol 16:234-244

24. Nie J, Liu X, Lilley BN et al (2013) SAD-A kinase controls islet beta-cell size and function as a mediator of mTORC1 signaling. Proc Natl Acad Sci U S A 110:13857-13862

25. Chen XY, Gu XT, Saiyin H et al (2012) Brain-selective kinase 2 (BRSK2) phosphorylation on PCTAIRE1 negatively regulates glucose-stimulated insulin secretion in pancreatic beta-cells. J Biol Chem 287:30368-30375 
26. Granot Z, Swisa A, Magenheim J et al (2009) LKB1 regulates pancreatic beta cell size, polarity, and function. Cell Metab 10: 296-308

27. Kone M, Pullen TJ, Sun G et al (2014) LKB1 and AMPK differentially regulate pancreatic beta-cell identity. FASEB J 28:49724985

28. Sun G, Tarasov AI, McGinty JA et al (2010) LKB1 deletion with the RIP2.Cre transgene modifies pancreatic beta-cell morphology and enhances insulin secretion in vivo. Am J Physiol Endocrinol Metab 298:E1261-E1273

29. Norton $\mathrm{M}, \mathrm{Ng} \mathrm{AC}$, Baird S et al (2014) ROMO1 is an essential redox-dependent regulator of mitochondrial dynamics. Sci Signal 7:ra10

30. Lam AK, Silva PN, Altamentova SM, Rocheleau JV (2012) Quantitative imaging of electron transfer flavoprotein autofluorescence reveals the dynamics of lipid partitioning in living pancreatic islets. Integr Biol (Camb) 4:838-846

31. Spigelman AF, Dai X, MacDonald PE (2010) Voltage-dependent $\mathrm{K}(+)$ channels are positive regulators of alpha cell action potential generation and glucagon secretion in mice and humans. Diabetologia 53:1917-1926

32. Allister EM, Robson-Doucette CA, Prentice KJ et al (2013) UCP2 regulates the glucagon response to fasting and starvation. Diabetes 62:1623-1633

33. Faubert B, Boily G, Izreig S et al (2013) AMPK is a negative regulator of the Warburg effect and suppresses tumor growth in vivo. Cell Metab 17:113-124
34. Yang MS, Gupta RC (2003) Determination of energy charge potential in the C6 glioma and the HepG-2 cell culture. Toxicol Mech Methods 13:97-101

35. Sturgess NC, Kozlowski RZ, Carrington CA, Hales CN, Ashford ML (1988) Effects of sulphonylureas and diazoxide on insulin secretion and nucleotide-sensitive channels in an insulin-secreting cell line. Br J Pharmacol 95:83-94

36. Komatsu M, Takei M, Ishii H, Sato Y (2013) Glucose-stimulated insulin secretion: a newer perspective. J Diabetes Investig 4:511-516

37. Pullen TJ, Sylow L, Sun G, Halestrap AP, Richter EA, Rutter GA (2012) Overexpression of monocarboxylate transporter-1 (SLC16A1) in mouse pancreatic beta-cells leads to relative hyperinsulinism during exercise. Diabetes 61:1719-1725

38. Metallo CM, Gameiro PA, Bell EL et al (2012) Reductive glutamine metabolism by IDH1 mediates lipogenesis under hypoxia. Nature 481:380-384

39. Fullerton MD, Galic S, Marcinko K et al (2013) Single phosphorylation sites in Acc1 and Acc2 regulate lipid homeostasis and the insulin-sensitizing effects of metformin. Nat Med 19:1649-1654

40. Li C, Buettger C, Kwagh J et al (2004) A signaling role of glutamine in insulin secretion. J Biol Chem 279:13393-13401

41. Zhang S, Kim KH (1998) Essential role of acetyl-CoA carboxylase in the glucose-induced insulin secretion in a pancreatic beta-cell line. Cell Signal 10:35-42

42. Ronnebaum SM, Joseph JW, Ilkayeva O et al (2008) Chronic suppression of acetyl-CoA carboxylase 1 in beta-cells impairs insulin secretion via inhibition of glucose rather than lipid metabolism. J Biol Chem 283:14248-14256 